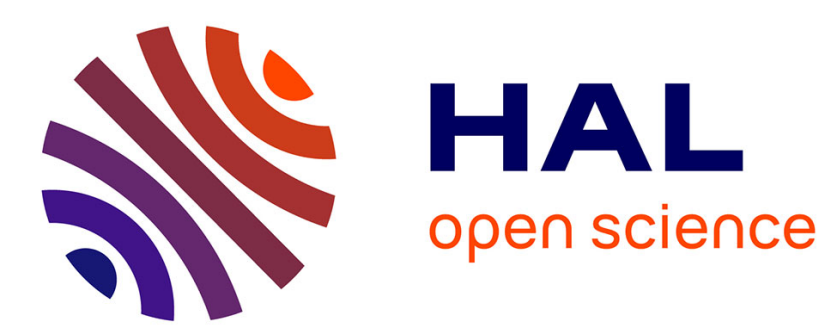

\title{
Accessory Proteins are vital for the functional expression of certain $\mathrm{G}$ protein-coupled receptors
}

Sadani N. Cooray, Li Chan, Tom R. Webb, Louise Metherell, Adrian J.L.

Clark

\section{- To cite this version:}

Sadani N. Cooray, Li Chan, Tom R. Webb, Louise Metherell, Adrian J.L. Clark. Accessory Proteins are vital for the functional expression of certain $\mathrm{G}$ protein-coupled receptors. Molecular and Cellular Endocrinology, 2009, 300 (1-2), pp.17. 10.1016/j.mce.2008.10.004 . hal-00532095

\section{HAL Id: hal-00532095 \\ https://hal.science/hal-00532095}

Submitted on 4 Nov 2010

HAL is a multi-disciplinary open access archive for the deposit and dissemination of scientific research documents, whether they are published or not. The documents may come from teaching and research institutions in France or abroad, or from public or private research centers.
L'archive ouverte pluridisciplinaire HAL, est destinée au dépôt et à la diffusion de documents scientifiques de niveau recherche, publiés ou non, émanant des établissements d'enseignement et de recherche français ou étrangers, des laboratoires publics ou privés. 


\section{Accepted Manuscript}

Title: Accessory Proteins are vital for the functional expression of certain $\mathrm{G}$ protein-coupled receptors

Authors: Sadani N. Cooray, Li Chan, Tom R. Webb, Louise Metherell, Adrian J.L. Clark

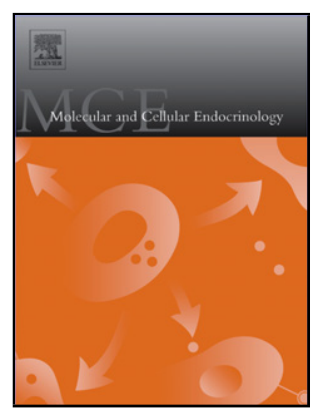

PII:

S0303-7207(08)00459-0

DOI: doi:10.1016/j.mce.2008.10.004

Reference: MCE 7018

To appear in: $\quad$ Molecular and Cellular Endocrinology

Received date: $\quad$ 7-8-2008

Revised date: 6-10-2008

Accepted date: $\quad 6-10-2008$

Please cite this article as: Cooray, S.N., Chan, L., Webb, T.R., Metherell, L., Clark, A.J.L., Accessory Proteins are vital for the functional expression of certain G protein-coupled receptors, Molecular and Cellular Endocrinology (2008), doi:10.1016/j.mce.2008.10.004

This is a PDF file of an unedited manuscript that has been accepted for publication. As a service to our customers we are providing this early version of the manuscript. The manuscript will undergo copyediting, typesetting, and review of the resulting proof before it is published in its final form. Please note that during the production process errors may be discovered which could affect the content, and all legal disclaimers that apply to the journal pertain. 


\section{Accessory Proteins are vital for the functional expression of certain G protein- coupled receptors}

Sadani N. Cooray, Li Chan, Tom R.Webb, Louise Metherell \& Adrian J.L.Clark

Centre for Endocrinology, William Harvey Research Institute, Barts and the London, London, UK.

Corresponding author: Prof. Adrian J.L. Clark, Centre for Endocrinology,

William Harvey Research Institute, Barts \& the London School of Medicine, Charterhouse Square, London EC1M 6BQ, UK

Tel: +44(0)2078828284,Fax: +44(0)278826197, e-mail: a.j.clark@qmul.ac.uk 


\begin{abstract}
Certain G protein-coupled receptors (GPCRs) fail to be expressed in a functional form at the cell surface. This may be due to the improper folding and maturation of GPCRs which are highly intricate events that need to take place before these integral membrane proteins can be transported from the endoplasmic reticulum (ER), where they are synthesised, to the plasma membrane which is their site of action. Once at the plasma membrane they act as the recognition elements for a vast range of endogenous ligands including biogenic amines, peptides, glycoproteins, lipids, nucleotides, ions and proteases. The assistance of molecular chaperones has been widely implicated in the trafficking and function of these proteins. Characterisation of certain GPCRs has identified a novel group of membrane proteins collectively named 'accessory proteins' as being important for the expression and function of GPCRs.
\end{abstract}

In this review we will summarise the importance of these accessory proteins for the function of their respective GPCRs. Understanding their roles in GPCR expression would not only give us an insight into these receptors from a cell biological point of view but may also potentially lead to the development of novel therapeutics. 


\section{Membrane trafficking and function of GPCRs}

G protein-coupled receptors (GPCRs) need to be expressed at the cell surface in order for them to have access to their ligands. GPCRs are synthesised within cells and need to assume a proper conformation before they are able to travel to, and insert themselves into, the cell membrane. However, only a small percentage of GPCRs are known to contain N-terminal signal peptides which are needed for translocation across the ER. On entering the ER their folding and assembly is constantly monitored by its quality control system. Improperly folded proteins are retained for refolding or degradation by the ubiquitin-proteosome pathway while properly folded proteins need to be exported from the ER to the cell surface (Castro-Fernandez et al, 2005; Conn et al, 2006). Inactivating mutations in GPCRs can lead to their intracellular retention and are known to give rise to a number of diseases including retinitis pigmentosa (rhodopsin receptor) (Mendes et al, 2005], hypogonadotropic hypogonadism (gonadotropin releasing hormone receptor) (Achermann et al, 2001), familial glucocorticoid deficiency (melanocortin 2 receptor) (Chan et al, 2008) and X-linked nephrogenic Diabetes insipidus (V2 vasopressin receptor) (Tan et al., 2004).

Until the mid 1990s it was believed that GPCRs existed as monomeric transmembrane proteins that interacted with a single $G$ protein upon ligand binding. It is now recognised that many GPCRs are able to form homo/heterodimers with other GPCRs and that dimerisation is important in the protein maturation and trafficking of these receptors (Bulenger et al, 2005). It is now apparent that GPCRs are able to interact with a wide range of proteins which are not G proteins or other GPCRs and that these proteins are vital for GPCR function (Brady and Limbird, 2002). In this review we will focus on the subset of these proteins that have a role in the correct folding and 
delivery of the receptor to the plasma membrane in a ligand-responsive and signalling-competent form.

\section{Molecular Chaperones in receptor function}

Molecular chaperones are a class of unrelated proteins that mediate the correct assembly of polypeptides thereby facilitating the folding of proteins. The chaperone concept was first proposed by Ellis and colleagues (Ellis, 1987) and since then it has stimulated an explosion of research into this field of significance to cell biologists, molecular pathologists and the pharmaceutical industry.

Chaperones are known to be able to recognise misfolded proteins (probably because of the exposure of the hydrophobic domains and thereby prevent inappropriate associations or aggregations of these domains (Tan et al., 2004). They are able to interact reversibly with incompletely folded protein subunits that emerge from ribosomes to minimise inappropriate interactions that can lead to irreversible conformations (Jaenicke, 1995), (Smith et al., 1998). Chaperones do not interact with native proteins or form part of the final folded structure and their expression is often increased by cellular stress. As part of the ER Quality Control System, chaperones are also known to be involved in protein targeting and degradation (Bukau et al, 2006). 


\section{Heat shock proteins}

Heat shock proteins (Hsps) have been implicated as the central components of the chaperone-protein folding system. Inappropriate protein folding can result from several physical and chemical conditions that could be hazardous to cells such as elevated temperature. This leads to the dramatic increase in Hsps that are able to resolve misfolded proteins and also bring back the normal protein-folding environment of cells (Parsell and Lindquist, 1993). Many Hsps and their cochaperones are constitutively expressed in all cells. There are several families of Hsps and individual members within the families that differ in their sequence and expression patterns as well as their functions. The Hsp families and their main functions are listed in Table 1.

The Hsp 70 chaperone machinery is one of the most studied examples of molecular chaperones and is composed of the Hsp 70 proteins themselves and their cochaperones the $\mathrm{J}$ proteins. The $\mathrm{J}$ protein family has previously been described by a number of terms including the DnaJ homologues, Hsp40 proteins, J-domain proteins or a combination of these names. Although it is known that there is about $50 \%$ amino acid conservation between the prokaryotic and eukaryotic Hsp 70 proteins, J protein family only show conservation within the $\mathrm{J}$ domain which is a single 70 amino acid domain (Cheetham and Caplan, 1998). The J domain has been found to stimulate the ATPase activity of Hsp 70 proteins and therefore these proteins are able to function as co-chaperones for the Hsp 70 chaperone machinery. J proteins can be classified into 
three sub-groups depending on their overall conservation with E.coli DnaJ. Type I J proteins have full domain conservation with DnaJ are called type I J proteins, while type II proteins have an $\mathrm{N}$ terminal- $\mathrm{J}$ domain as well as the GF (glycinephenylalanine)-rich region. Type III $\mathrm{J}$ proteins only have the $\mathrm{J}$ domain in common (Cheetham and Caplan, 1998).

Recent studies have suggested that small membrane-permeable compounds known as pharmacological chaperones can also enhance the processing and maturation of several wild-type and mutant GPCRs that are normally retained in the ER (Morello et al., 2000), (Noorwez et al., 2003). These pharmacological chaperones offer the potential to dramatically improve treatment options for patients with genetic disorders and certain pharmaceutical companies have already begun to develop orally active pharmacological chaperones for the treatment of diseases.

\section{Accessory Proteins in GPCR function}

The function of certain GPCRs is not only believed to be affected by their homo or heterodimerisation within the receptor family or by the use of molecular chaperones but also through their interaction with a novel group of proteins known as 'accessory proteins'. Although the exact mechanism by which they assist the functional expression of GPCRs is yet unclear they are believed to be involved in several aspects of GPCR activity. These accessory proteins can fall into one or more of the following categories.

(1) Proteins that play a similar role to molecular chaperones in assisting the correct folding of GPCRs, (2) Proteins that play a role as escort proteins in assisting the 
GPCRs to be trafficked out of the ER to the cell surface, (3) Proteins that are known to form part of the functional GPCR complex helping their retention at the cell surface during ligand binding. (4) Proteins that contribute to ligand specificity by either comprising part of the ligand binding pocket or by modulating the receptor conformation. (5) Proteins that are known to be associated with their GPCRs throughout their entire life cycle including being part of the desentisation and internalisation processes.

The importance of these membrane-associated accessory proteins in the normal expression of GPCRs was first established in studies carried out on Drosophila melanogaster rhodopsin and C. elegans chemosensory receptors. Since then several other GPCR accessory proteins have been identified. These include accessory proteins for the D1 dopamine receptor, the calcitonin-like receptor, odorant receptors, the calcium sensing receptor and most recently the melanocortin 2 receptor.

\section{Rhodopsin receptors, nina A and RanBP2}

Rh1 which is the predominant rhodopsin in Drosophila is synthesized in the endoplasmic reticulum of the photoreceptor cells and needs to be transported via the secretory pathway to the rabdomeres where it functions in phototransduction. The Drosophila cyclophilin gene ninaA ( $n$ either inactivation nor after potential $A$ ) which is an integral membrane protein has been found to be required for the biogenesis of rhodopsin (Shieh et al., 1989; Stamnes et al., 1991). Nina A exhibits peptidyl prolyl isomerase activity in vitro and therefore has been implicated in catalysing protein folding (Fischer et al., 1989; Takahashi et al., 1989). Immunocytochemistry and biochemical studies have shown that Rh1 accumulates in the ER and is unable to be 
transported to the rabdomeres in the absence of NinaA (Colley et al., 1991) resulting in the inappropriate processing of $\mathrm{Rh} 1$ which would eventually result in its degradation. This leads to a reduction in the amounts of rhodopsin which is characteristic of ninaA mutants where rhodopsin levels are found to be reduced by more than a 100-fold. Nina A has been shown to form a stable complex with rhodopsin from retinular cells R1-R6 (Baker et al., 1994). Nina A and rhodospin have also previously been shown to colocalise in transport vesicles (Colley et al., 1991). This has led to the suggestion that NinaA acts as a molecular chaperone presumably by isomerising the proline peptide bonds in Rh1 which may be required for its proper synthesis, folding or stability (Baker et al., 1994). In addition to its role in protein folding it is also suggested that NinaA may act as an accessory protein escorting rhodopsin through the secretory pathway (Baker et al., 1994).

RanBP2 (Ran binding protein 2) which is the mammalian homologue of ninaA is also expressed in a tissue specific manner in photoreceptor cells. The two contiguous domains in RanBP2; RBD4 (Ran binding domain 4) and cyclophilin are believed to act as a chaperone for the red/green opsin. However unlike Nina A, the cyclophilin domain of RanBP2 does not bind opsin directly. Nevertheless it is found to mediate the interaction between RBD4 and opsins possibly involving proline isomerisation thereby probably acting as a chaperone in the processing and transport of opsins (Colley et al., 1991; Ferreira et al., 1996). 


\section{Odorant receptors, ODR 4, RTPS $1 / 2$ and REEPI}

The olfactory receptors (ORs) are large and diverse families of GPCRs. ORs have been cloned from several taxonomic groups including mouse, dog, human, fish, chicken, nematodes and Drosophila. These receptors appear to have very little in common other than their general topology due to the large evolutionary distance between these organisms. ORs are found to be poorly expressed at the cell surface in heterologous cells and are usually retained at the ER and unable to reach the plasma membrane.

In 1998, it was found that a protein named ODR-4 (Odorant defective receptor) was necessary for the efficient targeting of odorant receptors to olfactory cilia in C.elegans chemosensory neurons (Dwyer et al., 1998). When expressed in heterologous cells, the odorant receptors are found to be trapped at the ER in the absence of ODR-4. ODR-4 localises at intracellular membrane compartments such as the ER, Golgi and transport vesicles in olfactory neurons and is thought to act as a molecular chaperone for the receptor by supporting its folding. It has also been suggested that ODR-4 may have a small effect on facilitating cell surface expression of one rat OR but not another (Gimelbrant et al., 1999).

Mammalian odorant receptors were first identified over 10 years ago (Buck and Axel, 1991). In an attempt to identify accessory proteins for mammalian ORs, receptor 
transporting proteins 1 and 2 (RTP 1 and RTP 2) which are expressed specifically by olfactory neurons were identified (Saito et al., 2004). RTP1 protein is 263 amino acids while RTP2 is 223 amino acids in length and they share $73 \%$ sequence identity at the amino acid level. Both proteins contain a single putative transmembrane domain and immunostaining experiments have revealed that the $\mathrm{N}$ terminus is intracellular while the $\mathrm{C}$ terminal end is extracellular. They were found to interact with OR proteins (MOR203-1, OREG, OR-S46, olfr62 and rat 17) and enhance response to odorants when expressed in HEK 293 cells (Saito et al., 2004).

Another olfactory neuron specific protein named receptor expression enhancing protein (REEP1) was shown to have a positive effect on expression of these OR $\mathrm{s}$ although it was found to be less effective than the RTPs. The REEPl gene encodes a 201 amino acid protein with two putative transmembrane domains. The $\mathrm{C}$ terminus of REEP1 is suggested to be extracellular (Saito et al., 2004). However REEP 1 was recently shown to be localized to the mitochondria and mutations in REEP 1 were found to be associated with hereditary spastic paraplegia (Zuchner et al., 2006). Another study showed that two other members of the RTP protein family RTP 3 and 4 and also REEP1 can influence the cell surface trafficking of the bitter taste receptors hTAS2R16 (Behrens et al., 2006). Although the precise mechanism of these accessory proteins in the activity of GPCRs is yet unclear it has been suggested that RTP1, RTP2 and REEP 1 may function as molecular chaperones promoting the correct folding of ORs and taste receptors at the ER. It is also suggested that they may facilitate the transport of ORs from the ER to the cell surface and/or even be associated as a co-receptor with ORs during ligand binding. 


\section{Dopamine receptor and DRiP78}

Dopamine receptor interacting protein 78 (DRiP78), an ER-membrane associated protein, is yet another protein that is implicated as an accessory protein for the trafficking of the D1 Dopamine receptor (Bermak et al., 2001). DRiP78 also known as DnaJc14/ DnaJ (Hsp40) homologue, subfamily C, member 14 contains two centrally located transmembrane domains with a putative cytosolic orientation for both the $\mathrm{N}$ and C-termini. DRiP78 is found to bind to the transport motif FxxxFxxx, within the C-terminus of the D1 Dopamine receptor at the ER and promotes its trafficking. Because this DRiP78 binding motif within the C-terminus is conserved in many GPCRs it has been suggested that DRiP78 may also regulate the export of other GPCRs. Recent studies have demonstrated a role for DRiP78 in the trafficking of AT1 angiotensin II receptors and M2 muscarinic acetylcholine receptors to the plasma membrane (Leclerc et al., 2002). It was recently suggested that DRiP 78 also plays a role as a molecular chaperone in the assembly of the $G$ protein subunits $G \beta / \gamma$ by protecting $\mathrm{G} \gamma$ from degradation until it associates appropriately with the $\mathrm{G} \beta$ subunit (Dupre et al., 2007).

\section{Calcitonin like- receptor and RAMPs}

Receptor activity modifying proteins (RAMPs) are a group of three related single transmembrane domain proteins that are necessary for the trafficking of the calcitonin-like receptor (CLR). CLR, which shows 55\% overall identity with the calcitonin receptor, was identified in 1993 and was presumed to be the receptor for 
calcitonin gene related peptide (CGRP) (Njuki et al., 1993). However, various attempts to show that it was indeed the CGRP receptor failed because of the failure to demonstrate any functional expression (Fluhmann et al., 1995).

Using an expression-cloning strategy to clone the gene encoding the receptor for CGRP, a new gene product was isolated that conferred CGRP signalling when expressed in Xenopus oocytes (McLatchie et al., 1998). This cDNA was isolated and found to encode a 148-amino acid protein containing a single transmembrane domain, a large extracellular $\mathrm{N}$-terminal domain and a short cytoplsmic tail. This was unexpected as it was assumed that this protein was the CGRP receptor and therefore it would be a seven transmembrane domain protein. However, further studies showed that RAMP1 by itself did not function as a receptor for CGRP but that the expression of RAMP1 with CLR resulted in CGRP binding and signalling.

Sequence data analysis and cloning experiments led to the identification of two further RAMP1-like proteins, which were named RAMP2 and RAMP3. Each of the RAMPs shares a similar basic structure but little amino acid sequence identity $(\sim 30 \%)$. However, experiments using these two proteins in human embryonic kidney (HEK293) cells and Xenopus oocytes showed that they did not allow the CLR to behave as a CGRP receptor, even though RAMPs 2 and 3 were as effective as RAMP1 in the trafficking of the CLR to the cell surface (McLatchie et al., 1998). Since the CLR, which was expressed at the cell surface with the aid of RAMP2 and 3, was not a conventional CGRP receptor, it was hypothesised that another ligand might activate this receptor. Adrenomedullin (ADM) was explored as the potential ligand as $\mathrm{ADM}$ and CGRP are related peptides and there was evidence that both CGRP and ADM receptors may exist in the lung where CLR, RAMP2 and RAMP3 were co- 
expressed. When CLR was co-expressed in HEK293 cells with RAMP2 or RAMP3 the cells responded preferentially to ADM and not to CGRP (Fig 1).

Although still not well established, RAMPs 1 and 3 have been shown to form stable homodimers (Heroux et al., 2007) which are even resistant to denaturing and reducing condition of SDS-PAGE. Although it is unlikely that the action of RAMPs in modifying receptor phenotype is affected by its homodimerisation it is possible that it may provide a mechanism to regulate the amount of available RAMP for interaction with the receptor.

Since the CLR is retained within the cell when expressed in the absence of RAMPs, these results led to the suggestion that RAMPs act as accessory proteins in the function of CLR.

All three RAMPs have been shown to enhance the expression of the CLR at the cell surface and likewise it has also been shown that the CLR needs to be coexpressed in cells in order for RAMPs to be translocated to the cell surface. (Fraser et al., 1999; Kuwasako et al., 2000). This suggests that RAMPs may act as molecular chaperones in facilitating the folding of CLR and also act as an escort to assist the CLR to the cell surface.

Studies have shown that RAMP1 is involved in the terminal glycosylation of the CLR and that RAMP1 can directly interact with both the immature and mature receptors with a stable interaction at the cell surface with the mature CLR (Hilairet et al., 2001). However neither RAMP2 nor RAMP3 is known to change the glycosylation pattern 
of CLR. RAMPs are typical examples of accessory proteins that act as activity modifiers by either comprising part of the ligand binding pocket or by modulating the receptor conformation. It has also been suggested that RAMPs may bind ligand directly since the partial deletion of the transmembrane domain of the RAMPs has led to a significant loss in CGRP potency despite normal trafficking of the receptor complex to the plasma membrane (Hilairet et al., 2001). Studies have also shown that the CLR, RAMP1 and arrestins can exist in a ternary complex in HEK 293 cells (Hilairet et al., 2001). This has led to the suggestion that RAMPs can associate with the CLR throughout its entire life cycle being an essential component of the desensitisation and internalisation machinary.

CLR is not the only receptor that interacts with RAMPs. Co-expression of RAMP1 and RAMP3 with the calcitonin receptor (CTR) allows this receptor to bind to amylin in addition to calcitonin. However, in this case RAMPs are not required for the trafficking of the receptor and only act as an activity modifier (Christopoulos et al., 1999). RAMPs 1 and 3 have also been shown to regulate the Calcium sensing receptor (CasR) from the ER to the Golgi and mediate the terminal glycosylation of the receptor (Bouschet et al., 2005), and several other members of the class B family of GPCRs have been shown to interact with RAMP proteins (Christopoulos et al., 2003)

\section{Melanocortin 2 receptor and MRAP}

Steroid biosynthesis in the adrenal cortex is under the control of Adrenocorticotropin $(\mathrm{ACTH})$ acting via the melanocortin 2 receptor $(\mathrm{MC} 2 \mathrm{R})$. Mutations in the $\mathrm{MC} 2 \mathrm{R}$ are associated with some forms of Familial Glucocorticoid Deficiency (FGD type 1). It 
has been extremely challenging to characterise the MC2R function in heterologous cells because of the lack of cell surface expression of the transfected receptor. When cells were transfected with the MC2R in non-adrenal cells the receptor was found to be retained at the ER suggesting that it may require an adrenal specific accessory factor for its cell surface expression and function (Noon et al., 2002). It was likely that defects in this accessory protein may be responsible for some forms of FGD with normal MC2R.

Investigation of families with members affected with ACTH insensitivity and a normal MC2R sequence identified a single gene on chromosome 21q22.1. This gene of 6 exons was found to encode a small single transmembrane domain protein of unknown function and was named Melanocortin 2 Receptor Accessory Protein (MRAP). Alternative splicing of the $5^{\text {th }}$ or $6^{\text {th }}$ exons give rise to MRAP $\alpha$ or $\beta$ respectively. In humans MRAP $\alpha$ encodes a protein of 172 amino acids, and MRAP $\beta$ encodes a protein of 102 amino acids. MRAP $\alpha$ and $\beta$ are identical at the $\mathrm{N}$-terminus and between residues $38-58$ of the predicted transmembrane domain but differ thereafter (Metherell et al., 2005).

\section{MRAP is essential for MC2R function}

Using confocal immunocytochemistry on non-adrenal cells transfected with epitope tagged MRAP and MC2R, it was demonstrated that the two proteins were able to colocalise with each other at the ER as well as at the cell surface. Therefore MRAP appeared to assist the cell surface trafficking of $\mathrm{MC} 2 \mathrm{R}$ which is otherwise found to be trapped at the ER presumably by acting as a chaperone and/or escort protein. The function of MC2R was also found to be significantly increased in the presence of 
MRAP compared to cells expressing MC2R alone as determined by the cAMP response to ACTH (Metherell et al., 2005; Roy et al., 2007). It has also been suggested that MC2R shows a higher maximal cAMP response to ACTH in the presence of MRAP $\beta$ compared to MRAP $\alpha$ (Roy et al., 2007).

However it is yet unclear whether like the RAMPs, MRAP would remain bound to the MC2R during ligand binding. The two proteins were shown to heterodimerise with each other by co-immunoprecipitation studies using epitope tagged MC2R and MRAP.

RNA interference studies (using both siRNAs and stable cell lines expressing shRNAs) knocking down the expression of endogenous MRAP in mouse Y1 adrenocortical cells resulted in a significant loss of function of the endogenous MC2R expressed in these cells as determined by the cAMP response to ACTH, further confirming the importance of MRAP in MC2R activity (Cooray et al., 2008).

Although MRAP shows no close parallels to other GPCR accessory proteins, it is a small single transmembrane domain protein like the RAMPs and RTPs. Immunocytochemistry and membrane prediction tools have suggested that the $\mathrm{N}$ terminus of MRAP is intracellular, similar to the RTPs (Metherell et al., 2005), although MRAP exists as a SDS-resistant homodimer particularly in cells of adrenal origin (Cooray et al., 2008). Recent data suggests that MRAP exists at the cell membrane as an antiparallel dimer (Sebag and Hinkle, 2007). Recent studies have also shown that MRAP2, which is a homologue of MRAP, also functions in a similar 
manner to MRAP in enhancing the function of the MC2R (Chan et al, manuscript submitted).

\section{Summary}

The export of certain GPCRs from the ER to the plasma membrane appears to be an extremely organised process. GPCRs can fail to fold correctly in a highly complex cellular environment and often result in the mislocalisation of the newly synthesised receptors leading to their inability to function properly in the cell. GPCRs are normally expressed at very low levels and therefore, accessory proteins may perform a crucial role to ensure the precise and efficient expression of functional receptors at the cell surface. Apart from NinaA and RanBP2 none of the GPCR accessory proteins discovered so far share any sequence homology with each other. The only common feature among all these proteins is their association with the cell membrane. There are still many questions that remain unanswered with regards to their actions. For example to what degree are they involved in directing receptor folding, receptor trafficking and function? Are there common transport mechanisms involved? Although GPCR accessory proteins are relatively novel and more progress needs to be made with regards to their functions, the possibility exists for developing potential therapeutic agents that would interfere or modulate vital GPCR- accessory protein interactions. 


\section{Figure legends}

\section{Figure 1:}

Heterodimerisaion of CLR and RAMPs. Co-expression of CLR with RAMP1 leads to the ability of the receptor to bind to CGRP. Co-expression of RAMP2 (or RAMP3) with CLR results in the binding of ADM.

\section{Figure 2:}

Summary of membrane associated accessory proteins in the trafficking of GPCRs from the ER to the cell surface: Drip78 (containing 2 transmembrane domains) is required for trafficking of the Dopamine D1 receptor. Nina A is required for Drosophila rhodopsin while its mammalian homologue RanBP2 assists the trafficking of mammalian opsins. RAMPs which posses single transmembrane domains are known to exist as dimers at the ER and are required for the function of the CLR. Several mammalian odorant receptors require the single transmembrane domain proteins RTP 1 and 2 and are linked to a weaker extent with REEP1 containing two transmembrane domains. ODR4 enhances the function of the C.elegans odorant receptors. MRAP which is also a small single transmembrane protein is essential for the function of the melanocortin 2 receptor.

\section{Figure 3:}

The subcellular localisation of MC2R and its accessory protein MRAP: When MC2R is transfected into cells of non adrenal origin it is found to be retained at the ER unable to be expressed at the cell surface (top panel). MRAP is also associated with the ER when transfected into cells colocalising with the ER specific marker 
Calnexin (middle panel). Green indicates MRAP $\alpha$-Flag transfected cells stained with a cy2 conjugated secondary antibody. Shown in red are cells stained with the Calnexin-cy3 conjugated marker and yellow indicates the co localisation of MRAP $\alpha$ and Calnexin. When MC2R-GFP (green) and MRAP $\alpha$-Flag (red) are co-transfected into cells, the receptor and MRAP co-localise at the plasma membrane in the lower cell - shown as yellow in the merged image - arrowed. In the upper cell, MRAP $\alpha-$ Flag transient transfection failed and the transfected MC2R-GFP remains trapped in the ER. (Lower panel reproduced with permission from Cooray et al, Adrenocorticotropin Resistance Syndromes in 'Disorders of the Human Adrenal Cortex', eds Fluck CE \& Miller WL, Endocrine Development, Basel, Karger, 2008 13: $99-116)$.

\section{Table 1:}

\section{Hsp families and their functions}




\section{References}

Achermann, J.C., Weiss, J., Lee, E.J. \& Jameson, J.L. 2001 Inherited disorders of the gonadotropin hormones. Mol Cell Endocrinol. 179: 89-96

Baker, E. K., Colley, N. J., \& Zuker, C. S. 1994, The cyclophilin homolog NinaA functions as a chaperone, forming a stable complex in vivo with its protein target rhodopsin, EMBO J.,. 13, 20, 4886-4895.

Behrens, M., Bartelt, J., Reichling, C., Winnig, M., Kuhn, C., \& Meyerhof, W. 2006, Members of RTP and REEP gene families influence functional bitter taste receptor expression, J.Biol.Chem.,. 281:. 20650-20659.

Bermak, J. C., Li, M., Bullock, C., \& Zhou, Q. Y. 2001, Regulation of transport of the dopamine D1 receptor by a new membrane-associated ER protein, Nat.Cell Biol.,. 3, 492-498.

Bouschet, T., Martin, S., \& Henley, J. M. 2005, Receptor-activity-modifying proteins are required for forward trafficking of the calcium-sensing receptor to the plasma membrane, J.Cell Sci.,. 118: 4709-4720.

Brady, A. E. \& Limbird, L. E. 2002, G protein-coupled receptor interacting proteins: emerging roles in localization and signal transduction, Cell Signal.. 14: 297-309.

Buck, L. \& Axel, R. 1991, A novel multigene family may encode odorant receptors: a molecular basis for odor recognition, Cell, 65: 175-187.

Bukau, B., Weissman, J. \& Horwich, A. 2006 Molecular chaperones and protein quality control. Cell. 125: 443-51. 
Bulenger, S., Marullo, S. \& Bouvier, M. 2005 Emerging role of homo- and heterodimerization in G-protein-coupled receptor biosynthesis and maturation. Trends Pharmacol Sci. 26:131-7.

Castro-Fernández, C., Maya-Núñez, G. \& Conn, P.M. 2005 "Beyond the signal sequence: protein routing in health and disease". Endocr Rev. 26: 479-503

Chan, L.F., Clark, A.J. \& Metherell, L.A. 2008 Familial glucocorticoid deficiency: advances in the molecular understanding of ACTH action. Horm Res. 69:75-82.

Cheetham, M. E. \& Caplan, A. J. 1998, Structure, function and evolution of DnaJ: conservation and adaptation of chaperone function, Cell Stress.Chaperones., 3: 28-36.

Christopoulos, G., Perry, K. J., Morfis, M., Tilakaratne, N., Gao, Y., Fraser, N. J., Main, M. J., Foord, S. M., \& Sexton, P. M. 1999, Multiple amylin receptors arise from receptor activity-modifying protein interaction with the calcitonin receptor gene product, Mol.Pharmacol.,. 56: 235-242.

Christopoulos, A., Christopoulos, G., Morfis, M., Udawela, M., Laburthe, M., Couvineau, A., Kuwasako, K., Tilakaratne, N., \& Sexton, P. M. 2003, Novel receptor partners and function of receptor activity-modifying proteins, J.Biol.Chem.,. 278: 3293-3297.

Colley, N. J., Baker, E. K., Stamnes, M. A., \& Zuker, C. S. 1991, The cyclophilin homolog ninaA is required in the secretory pathway, Cell,. 67: 255-263. 
Conn, P.M., Janovick, J.A., Brothers, S.P. \& Knollman, P.E. 2006 Effective inefficiency': cellular control of protein trafficking as a mechanism of posttranslational regulation. J Endocrinol. 190:13-6

Cooray, S. N., Almiro, D. V., I, Leung, K. Y., Webb, T. R., Chapple, J. P., Egertova, M., Cheetham, M. E., Elphick, M. R., \& Clark, A. J. 2008, The melanocortin 2 receptor accessory protein exists as a homodimer and is essential for the function of the melanocortin 2 receptor in the mouse Y1 cell line, Endocrinology,. 149: 19351941.

Csermely, P., Schnaider, T., Soti, C., Prohaszka, Z., \& Nardai, G. 1998, The 90-kDa molecular chaperone family: structure, function, and clinical applications. A comprehensive review, Pharmacol.Ther.,79: 129-168.

Dupre, D. J., Robitaille, M., Richer, M., Ethier, N., Mamarbachi, A. M., \& Hebert, T. E. 2007, Dopamine receptor-interacting protein 78 acts as a molecular chaperone for Ggamma subunits before assembly with G beta, J.Biol.Chem.,. 282: 13703-13715.

Dwyer, N. D., Troemel, E. R., Sengupta, P., \& Bargmann, C. I. 1998, Odorant receptor localization to olfactory cilia is mediated by ODR-4, a novel membraneassociated protein, Cell,. 93: 455-466.

Ellis, J. 1987, Proteins as molecular chaperones, Nature,. 328: 378-379.

Ferreira, P. A., Nakayama, T. A., Pak, W. L., \& Travis, G. H. 1996, Cyclophilinrelated protein RanBP2 acts as chaperone for red/green opsin, Nature,. 383: 637-640. 
Fischer, G., Wittmann-Liebold, B., Lang, K., Kiefhaber, T., \& Schmid, F. X. 1989, Cyclophilin and peptidyl-prolyl cis-trans isomerase are probably identical proteins, Nature,. 337: 476-478.

Fluhmann, B., Muff, R., Hunziker, W., Fischer, J. A., \& Born, W. 1995, A human orphan calcitonin receptor-like structure, Biochem.Biophys.Res.Commun.,. 206: 341347.

Fraser, N. J., Wise, A., Brown, J., McLatchie, L. M., Main, M. J., \& Foord, S. M. 1999, The amino terminus of receptor activity modifying proteins is a critical determinant of glycosylation state and ligand binding of calcitonin receptor-like receptor, Mol.Pharmacol.,. 55: 1054-1059.

Gimelbrant, A. A., Stoss, T. D., Landers, T. M., \& McClintock, T. S. 1999, Truncation releases olfactory receptors from the endoplasmic reticulum of heterologous cells, J.Neurochem.,. 72: 2301-2311.

Hartl, F. U. 1996, Molecular chaperones in cellular protein folding, Nature,. 381: 571579.

Heikkila, J. J., Kaldis, A., \& Abdulle, R. 2006, Analysis of molecular chaperones using a Xenopus oocyte protein refolding assay, Methods Mol.Biol.,. 322: 213-222.

Heroux, M., Breton, B., Hogue, M., \& Bouvier, M. 2007, Assembly and signaling of CRLR and RAMP1 complexes assessed by BRET, Biochemistry,. 46: 7022-7033.

Hilairet, S., Belanger, C., Bertrand, J., Laperriere, A., Foord, S. M., \& Bouvier, M. 2001, Agonist-promoted internalization of a ternary complex between calcitonin 
receptor-like receptor, receptor activity-modifying protein 1 (RAMP1), and betaarrestin, J.Biol.Chem.,. 276: 42182-42190.

Houry, W. A. 2001, Chaperone-assisted protein folding in the cell cytoplasm, Curr.Protein Pept.Sci.,. 2: 227-244.

Jaenicke, R. 1995, Folding and association versus misfolding and aggregation of proteins, Philos.Trans.R.Soc.Lond B Biol.Sci.,. 348: 97-105.

Kuwasako, K., Shimekake, Y., Masuda, M., Nakahara, K., Yoshida, T., Kitaura, M., Kitamura, K., Eto, T., \& Sakata, T. 2000, Visualization of the calcitonin receptor-like receptor and its receptor activity-modifying proteins during internalization and recycling, J.Biol.Chem.,. 275: 29602-29609.

Leclerc, P. C., Auger-Messier, M., Lanctot, P. M., Escher, E., Leduc, R., \& Guillemette, G. 2002, A polyaromatic caveolin-binding-like motif in the cytoplasmic tail of the type 1 receptor for angiotensin II plays an important role in receptor trafficking and signaling, Endocrinology,. 143: 4702-4710.

McLatchie, L. M., Fraser, N. J., Main, M. J., Wise, A., Brown, J., Thompson, N., Solari, R., Lee, M. G., \& Foord, S. M. 1998, RAMPs regulate the transport and ligand specificity of the calcitonin-receptor-like receptor, Nature,. 393: 333-339.

Mendes, H.F., van der Spuy, J., Chapple, J.P. \& Cheetham, M.E. 2005 Mechanisms of cell death in rhodopsin retinitis pigmentosa: implications for therapy. Trends Mol Med. 11:177-85.

Metherell, L. A., Chapple, J. P., Cooray, S., David, A., Becker, C., Ruschendorf, F., Naville, D., Begeot, M., Khoo, B., Nurnberg, P., Huebner, A., Cheetham, M. E., \& Clark, A. J. 2005, Mutations in MRAP, encoding a new interacting partner of the 
ACTH receptor, cause familial glucocorticoid deficiency type 2, Nat.Genet.,. 37: 166170.

Morello, J. P., Salahpour, A., Laperriere, A., Bernier, V., Arthus, M. F., Lonergan, M., Petaja-Repo, U., Angers, S., Morin, D., Bichet, D. G., \& Bouvier, M. 2000, Pharmacological chaperones rescue cell-surface expression and function of misfolded V2 vasopressin receptor mutants, J.Clin.Invest,. 105: 887-895.

Njuki, F., Nicholl, C. G., Howard, A., Mak, J. C., Barnes, P. J., Girgis, S. I., \& Legon, S. 1993, A new calcitonin-receptor-like sequence in rat pulmonary blood vessels, Clin.Sci.(Lond),. 85: 385-388.

Noon, L. A., Franklin, J. M., King, P. J., Goulding, N. J., Hunyady, L., \& Clark, A. J. 2002, Failed export of the adrenocorticotrophin receptor from the endoplasmic reticulum in non-adrenal cells: evidence in support of a requirement for a specific adrenal accessory factor, J.Endocrinol.,. 174: 17-25.

Noorwez, S. M., Kuksa, V., Imanishi, Y., Zhu, L., Filipek, S., Palczewski, K., \& Kaushal, S. 2003, Pharmacological chaperone-mediated in vivo folding and stabilization of the $\mathrm{P} 23 \mathrm{H}-o p s i n$ mutant associated with autosomal dominant retinitis pigmentosa, J.Biol.Chem.,. 278: 14442-14450.

Parsell, D. A. \& Lindquist, S. 1993, The function of heat-shock proteins in stress tolerance: degradation and reactivation of damaged proteins, Annu.Rev.Genet.,. 27: 437-496.

Roy, S., Rached, M., \& Gallo-Payet, N. 2007, Differential regulation of the human adrenocorticotropin receptor [melanocortin-2 receptor (MC2R)] by human MC2R 
accessory protein isoforms alpha and beta in isogenic human embryonic kidney 293 cells, Mol.Endocrinol.,. 21: 1656-1669.

Saito, H., Kubota, M., Roberts, R. W., Chi, Q., \& Matsunami, H. 2004, RTP family members induce functional expression of mammalian odorant receptors, Cell, . 119: 679-691.

Schirmer, E. C., Glover, J. R., Singer, M. A., \& Lindquist, S. 1996, HSP100/Clp proteins: a common mechanism explains diverse functions, Trends Biochem.Sci.,. 21: 289-296.

Sebag, J. A. \& Hinkle, P. M. 2007, Melanocortin-2 receptor accessory protein MRAP forms antiparallel homodimers, Proc.Natl.Acad.Sci.U.S.A,. 104: 20244-20249.

Shieh, B. H., Stamnes, M. A., Seavello, S., Harris, G. L., \& Zuker, C. S. 1989, The ninaA gene required for visual transduction in Drosophila encodes a homologue of cyclosporin A-binding protein, Nature ,. 338: 67-70.

Smith, D. F., Whitesell, L., \& Katsanis, E. 1998, Molecular chaperones: biology and prospects for pharmacological intervention, Pharmacol.Rev.,. 50: 493-514.

Stamnes, M. A., Shieh, B. H., Chuman, L., Harris, G. L., \& Zuker, C. S. 1991, The cyclophilin homolog ninaA is a tissue-specific integral membrane protein required for the proper synthesis of a subset of Drosophila rhodopsins, Cell,. 65: 219-227.

Takahashi, N., Hayano, T., \& Suzuki, M. 1989, Peptidyl-prolyl cis-trans isomerase is the cyclosporin A-binding protein cyclophilin, Nature, . 337: 473-475. 
Tan, C. M., Brady, A. E., Nickols, H. H., Wang, Q., \& Limbird, L. E. 2004, Membrane trafficking of G protein-coupled receptors, Annu.Rev.Pharmacol.Toxicol.,. 44: 559-609.

Welch, W. J. 1993, Heat shock proteins functioning as molecular chaperones: their roles in normal and stressed cells, Philos.Trans.R.Soc.Lond B Biol.Sci.,. 339: 327-333.

Zuchner, S., Wang, G., Tran-Viet, K. N., Nance, M. A., Gaskell, P. C., Vance, J. M., Ashley-Koch, A. E., \& Pericak-Vance, M. A. 2006, Mutations in the novel mitochondrial protein REEP1 cause hereditary spastic paraplegia type 31, Am.J.Hum.Genet.,. 79: 365-369. 
Table 1

\begin{tabular}{lll}
\hline Family & Major functions & Reference \\
\hline Hsp100 & Protein degradation, thermotolerance & (Schirmer et al., 1996) \\
Hsp90 & Stabilisation of misfolded proteins & (Csermely et al., 1998) \\
Hsp70 & Protein folding, membrane transport of proteins & (Hartl, 1996) \\
Hsp60 & Protein folding & (Welch, 1993) \\
Hsp40 & Protein folding and a co-chaperone for Hsp 70 & (Houry, 2001) \\
Small Hsp & Stabilisation of misfolded proteins, & (Heikkila et al., 2006) \\
& thermotolerance & \\
\hline
\end{tabular}


Figure 1

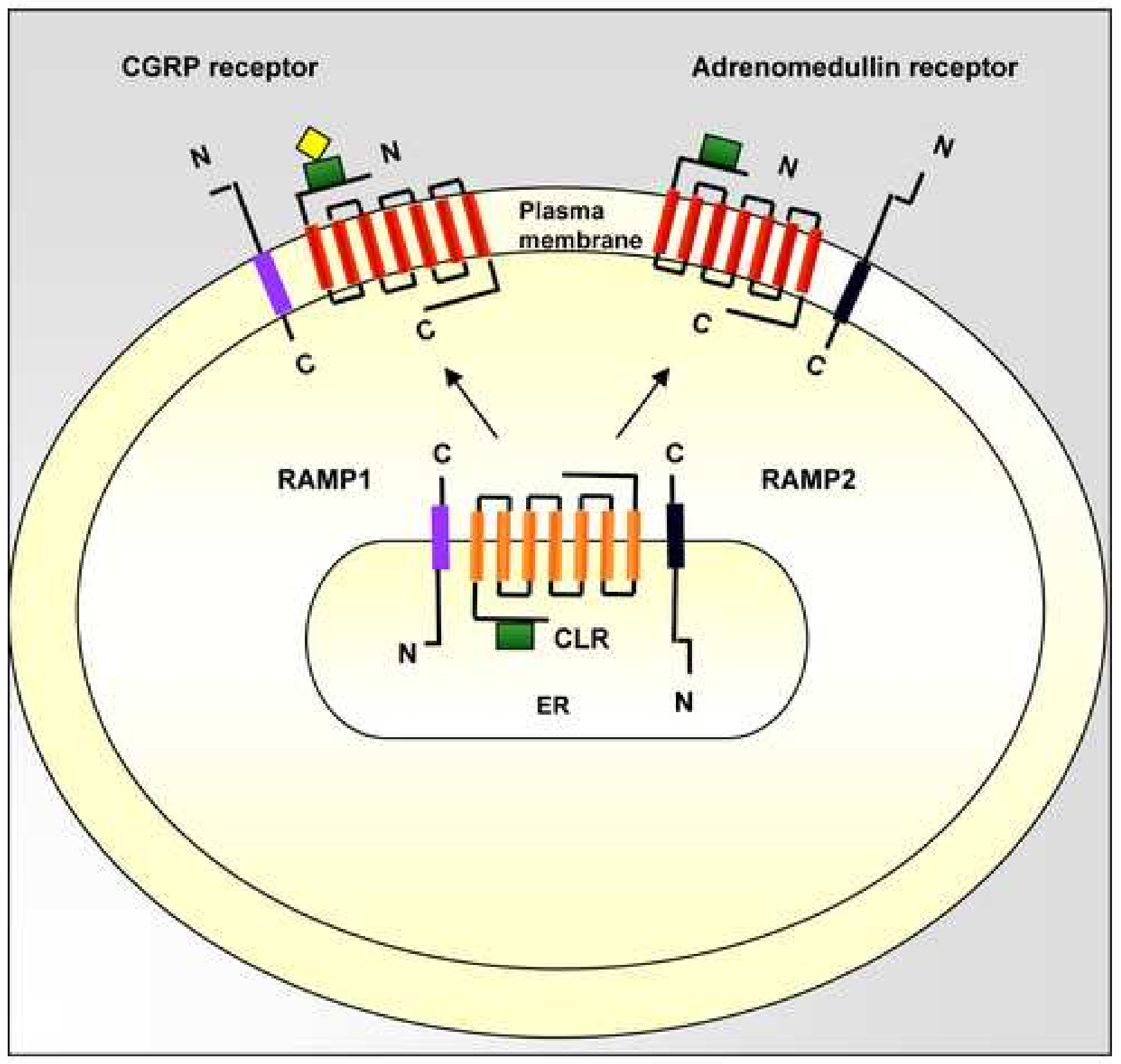

$\diamond$ Terminal glycosylation $\quad \square$ Core glycosylation 
Figure 2

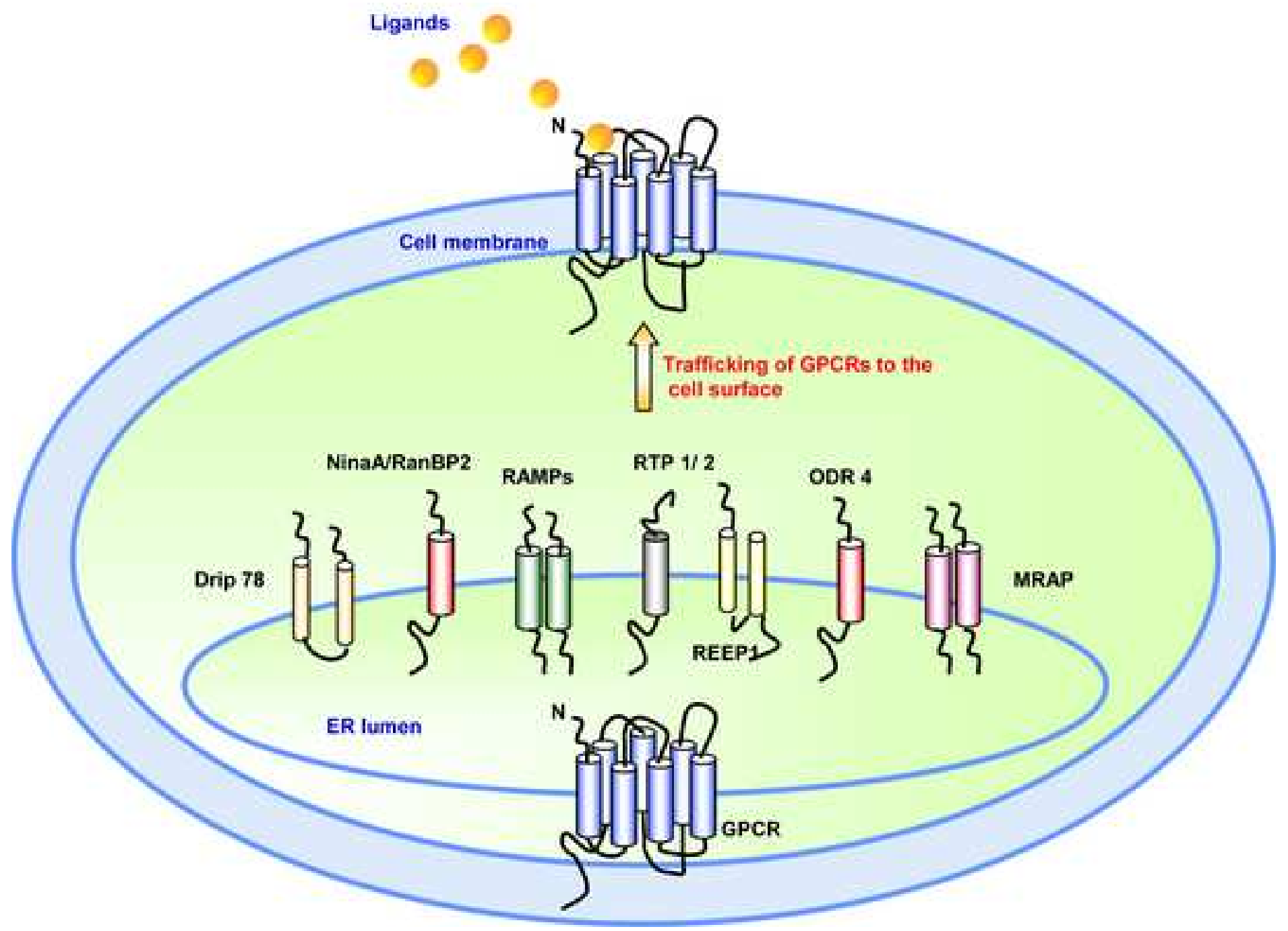


Figure 3

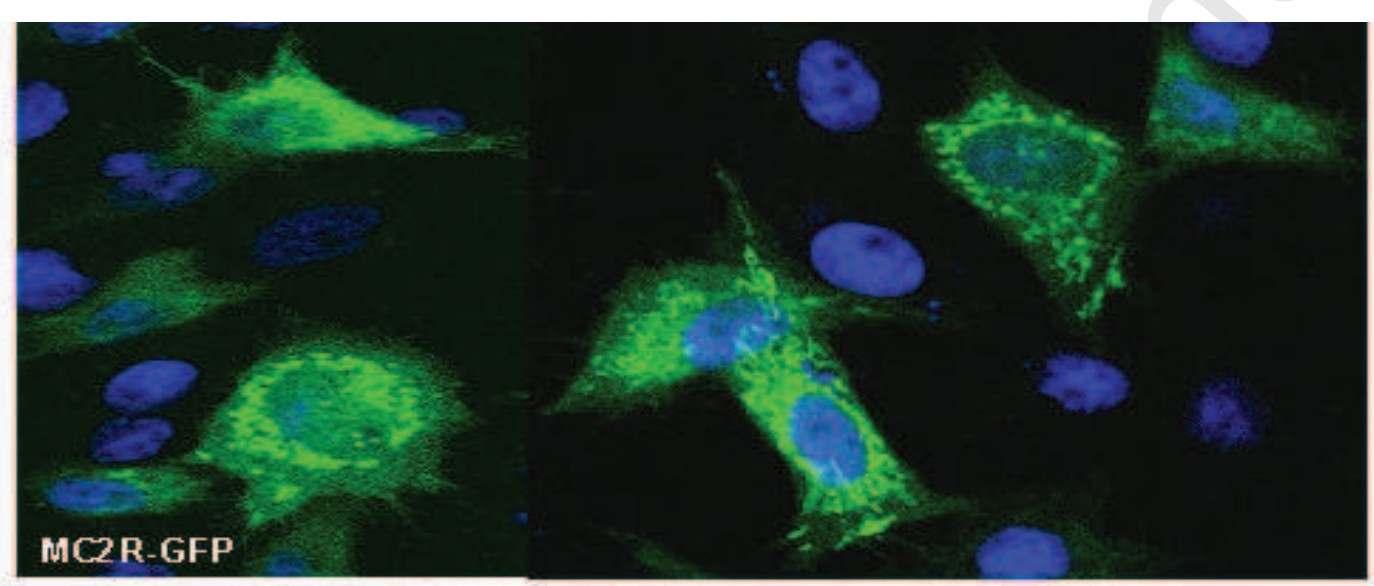

MRAP o-Flag

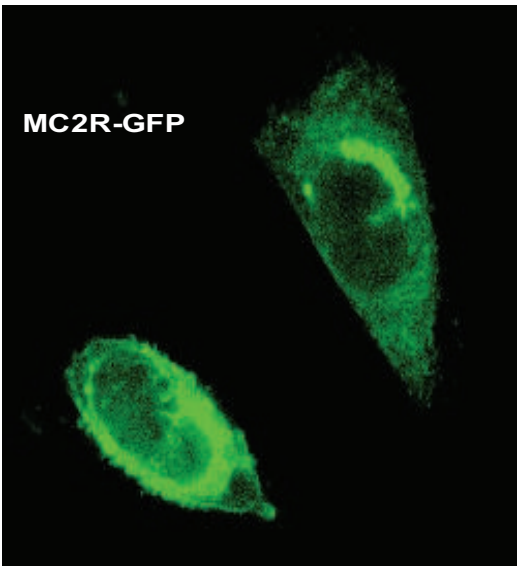

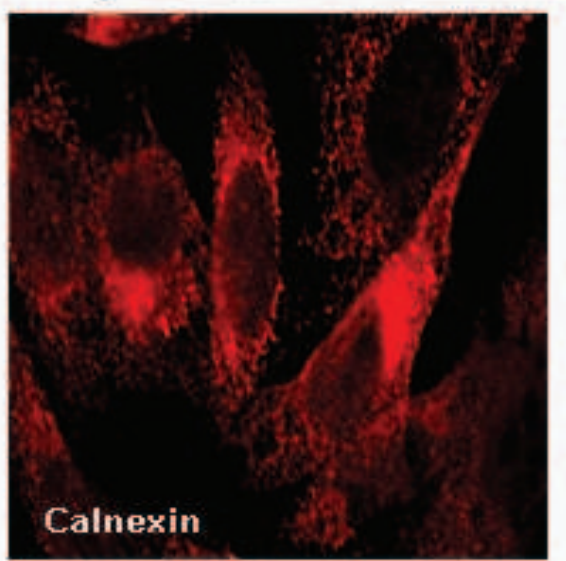
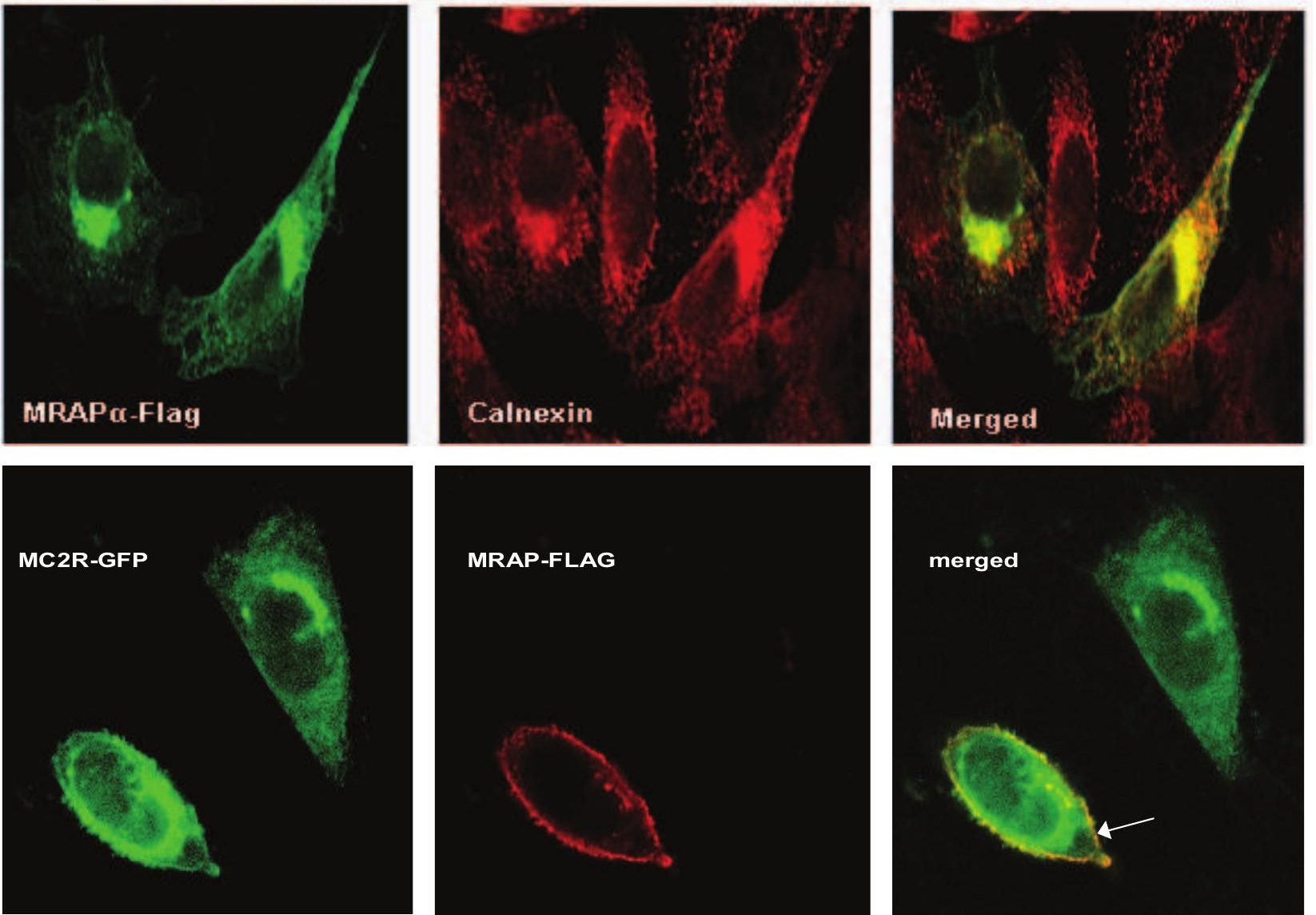

Page 31 of 31 